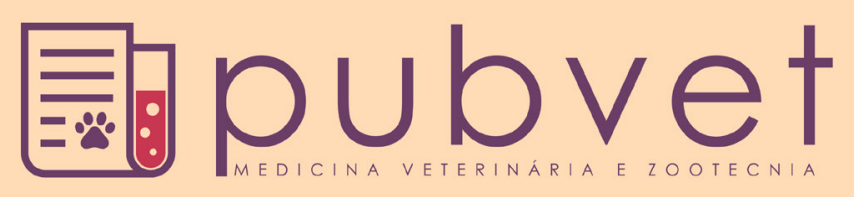

HTTP://DX.DOI.ORG/10.22256/PUBVET.V11N5.470-475

\title{
Inquérito soro-epidemiológico de Brucella ovis e Brucella abortus em rebanhos ovinos pertencentes à microrregião de Teresina, Brasil
}

\author{
Gardenia Alves da Silva ${ }^{1}$, Ana Gabriela Pereira Moura Leite ${ }^{2}$, Letícia Soares de Araújo \\ Teixeira $^{1,}$ Estéfane Kelly Dias Araújo ${ }^{2 *}$, Misael Santana das Virgens ${ }^{2}$, Rômulo José \\ Vieira $^{3}$, Ana Lys Bezerra Barradas Mineiro ${ }^{3}$
}

${ }^{1}$ Médica Veterinária, Universidade Federal do Piaui (UFPI). Teresina, Piauí, Brasil

${ }^{2}$ Graduanda em Medicina Veterinária, Universidade Federal do Piaui (UFPI). Teresina, Piauí, Brasil.

${ }^{3}$ Professor(a) da Universidade Federal do Piauí (UFPI). Teresina, Piauí, Brasil

*Autor para correspondência por e-mail: estefane-kelly@hotmail.com

RESUMO. O objetivo desse estudo foi realizar uma investigação epidemiológica da ocorrência de Brucella ovis e Brucella abortus nos rebanhos ovinos de municípios pertencentes à microrregião de Teresina, Piauí, Brasil. Foram analisadas amostras de 521 animais. A colheita de sangue foi realizada por venopunção e os tubos contendo as amostras foram encaminhados ao Laboratório de Fisiopatologia da Reprodução dos Animais Domésticos da Universidade Federal do Piauí para posterior análise. A pesquisa de anticorpos anti-Brucella ovis e anti- Brucella abortus foi realizada por meio das técnicas de Imunodifusão em Gel de Agar (IDGA) e Antígeno Acidificado Tamponado (AAT) respectivamente. Aos proprietários dos rebanhos foi aplicado um questionário contendo questões sobre os aspectos gerais da propriedade, do rebanho, manejo reprodutivo e sanitário dos animais. Não foram encontrados animais soropositivos para Brucella abortus. $53,6 \%$ das propriedades investigadas apresentaram pelo menos um caso de ovino soropositivo para Brucella ovis pelo teste de IDGA. 4,6\% das amostras foram positivas para anticorpos anti- Brucela ovis. Das amostras positivas, 8,67\% eram fêmeas e 1,02\% machos. $13,6 \%$ das amostras positivas foram de animais com idade superior a 36 meses. $\mathrm{O}$ principal tipo de sistema de criação foi o extensivo. Em $28,6 \%$ das propriedades foi relatada a ocorrência de abortos. $7,1 \%$ das propriedades não realizavam nenhum manejo sanitário e somente $39,2 \%$ das propriedades recebiam algum tipo de assistência técnica. Com base nos achados deste estudo pode se concluir que a microrregião de Teresina está exposta a contaminação por Brucella ovis e o manejo sanitário e reprodutivo nas propriedades é deficiente, assim como a assistência técnica é pouco requisitada pelos produtores, prejudicando o controle e prevenção da brucelose ovina.

Palavras chaves: Brucelose, manejo, ovinos

\section{Brucella ovis and Brucella abortus in sheep herds of Teresina, Brasil}

ABSTRACT. The purpose of this study was to conduct an epidemiological investigation on the occurrence of Brucella ovis and Brucella abortus in sheep flocks at municipalities belonging to the microregion of Teresina, Piauí, Brazil. Samples from 521 animals were analyzed. It was performed blood collection by venous access, and the tubes containing the samples were sent to the Laboratory of Pathophysiology of Reproduction of Domestic Animals of the Federal University of Piauí, for later analysis. It was performed the antibodies detection for anti-Brucella ovis and anti-Brucella abortus using the Agar Gel Immunodiffusion (AGID) and Buffered Acidified Antigen (AAT) techniques, respectively. A questionnaire, containing questions on the general aspects of the property, the herd, 
reproductive and sanitary management of the animals, was applied to the owners of the herds. No animals were found seropositive for Brucella abortus. 53.6\% of the properties investigated had at least one case of sheep seropositive for Brucella ovis by AGID test. $4.6 \%$ of the samples were positive for antibodies anti-Brucella ovis. About the positive samples, $8.67 \%$ were females and $1.0 \%$ males. $13.6 \%$ of positive samples were about animals aged more than 36 months. The main type of breeding system was the extensive. It was reported abortions incidents in about $28,6 \%$ of the properties. $7.1 \%$ of the properties did not perform any sanitary management and only $39.2 \%$ of the properties received some type of technical assistance. Based on the findings of this study, it can be concluded that the micro-region of Teresina is exposed to the contamination of Brucella ovis, and sanitary and reproductive management is defective in the properties, as well as the technical assistance is little requested by the producers, impairing the control and prevention of ovine brucellosis.

Keywords: Brucellosis, management, ovines

\section{Investigación suero-epidemiológica de Brucella ovis y Brucella abortus en rebaños de ovejas de la micro-región de Teresina, Brasil}

RESUMEN. El objetivo de este estudio fue realizar una investigación epidemiológica de la presencia de Brucella ovis y Brucella abortus en los rebaños de ovejas de municipios pertenecientes a la micro-región de Teresina, Piauí, Brasil. Se analizaron muestras de 521 animales. Las colecta de las muestras de sangre se realizaron por medio de punción venosa y los tubos con muestras se enviaron al laboratorio de fisiopatología de reproducción de animales domésticos de la Universidad Federal de Piaú para posteriores análisis. La investigación de anticuerpos de Brucella ovis y Brucella abortus se llevó a cabo por medio de técnicas de inmunodifusión en gel de Agar (IDGA) y antígeno antiacidificado de placa tamponada (AAT), respectivamente. Se realizó un cuestionario a los propietarios de los rebaños y se les preguntó sobre aspectos generales de la propiedad, del hato, el manejo reproductivo y sanitario de los animales. No se encontraron animales seropositivos para Brucella abortus. $53,6 \%$ de las propiedades investigadas tenía por lo menos un caso seropositivo para Brucella ovis por prueba IGDA. 4,6\% de las muestras fueron positivas para anticuerpos anti Brucella ovis. De las muestras positivas, 8,67\% eran hembras y 1,02\% machos. 13,6\% de las muestras seropositivas eran de animales de edad superior a 36 meses. El principal tipo de sistema de producción fue extensivo. En el $28,6 \%$ de las propiedades fue informada la existencia de abortos. $7,1 \%$ de las propiedades no realizaban ninguna gestión sanitaria y sólo el 39,2\% de las propiedades recibían algún tipo de asistencia técnica. Con base en los resultados de este estudio se puede concluir que la micro-región de Teresina está expuesta a la contaminación por Brucella ovis y la gestión sanitaria y reproductiva en las propiedades es deficiente, así como la asistencia técnica que es poco solicitada por los productores, perjudicando el control y la prevención de la brucelosis en el ganado ovino.

Palabras clave: Brucelosis, manejo, ovejas

\section{Introdução}

A ovinocultura é uma atividade que vem ganhando grande destaque no cenário agropecuário brasileiro, e desta maneira, influenciando o desenvolvimento sócio econômico do país, entretanto, ainda enfrenta dificuldades no controle de determinadas doenças que acometem os rebanhos, podendo ocasionar grandes perdas econômicas aos produtores, assim como tornarem-se agravantes na esfera da saúde pública (Marinho et al., 2012).

A brucelose é uma enfermidade de grande importância na medicina reprodutiva dos animais de produção, de ocorrência mundial e que pode acometer animais e seres humanos. É ocasionada pela Brucella sp., que se caracterizam por serem bactérias gram-negativas e intracelulares facultativas (Souza et al., 2009, Seleem et al., 2010). Nos ovinos ocorre pela ação da bactéria 
Brucella ovis, que é transmitida no período de reprodução do rebanho e se caracteriza por quadros de epididimite, orquite e abortos, contribuindo para a diminuição da fertilidade dos animais (Costa et al., 2012).

A região nordeste do Brasil se caracteriza pela presença de muitas criações ovinas, sendo uma área propicia a disseminação da brucelose devido ao tipo de sistema de criação extensivo a que são submetidos os animais. Em outros estados nordestinos já foram registrados elevados índices de animais contaminados por Brucella ovis, demonstrando a importância de estudos neste campo de pesquisas em outras regiões brasileiras (Pinheiro Junior et al., 2009).

Em um estudo realizado por Santos et al. (2013) no sertão do estado da Paraíba, Brasil, com o objetivo de determinar a prevalência de animais soropositivos para Brucella ovis foi constatado que $20,4 \%$ das propriedades pesquisadas continham animais infectados e apresentaram como fatores de risco a higiene das instalações e aquisição de novos animais sem prévio exame para diagnóstico de brucelose, o que caracteriza elevada importância de pesquisas de caráter epidemiológico que visem compreender a atuação dessa enfermidade e assim controlar sua propagação.

A criação consorciada de ovinos e outras espécies animais destinadas a produção pode ocasionar a infecção de carneiros e ovelhas por outros tipos de Brucella sp., como a Brucella abortus que é responsável por grandes perdas econômicas em rebanhos bovinos e pode estar relacionada a disseminação da brucelose em outras espécies domésticas, assim como no homem (Lawinsky et al., 2010).

Nos seres humanos é considerada uma enfermidade de caráter ocupacional e classificada como doença emergente pela Organização Mundial da Saúde. O diagnóstico da brucelose em humanos ainda não possui uma rede estruturada na saúde pública do Brasil, sendo necessários maiores investimentos em medidas de vigilância que impeçam a disseminação da doença (Lawinsky et al., 2010).

A técnica de imunodifusão em gel de agar (IDGA) é o principal teste sorológico utilizado para detecção da Brucella ovis por apresentar elevada sensibilidade e especificidade, podendo ser associado a outros testes bacteriológicos, assim como PCR afim de aumentar a eficiência do diagnóstico (Xavier et al., 2011). O controle de infecções ocasionadas pelo gênero Brucella $s p$. é realizado por meio da adoção de medidas sanitárias que visem diminuir a disseminação do patógeno no plantel de animais, o que contribui de forma direta para diminuição da doença em humanos (Salaberry et al., 2011).

Diante da escassez de dados sobre a atual prevalência de brucelose nos rebanhos ovinos do estado do Piauí, Brasil, objetivou-se realizar uma investigação epidemiológica da ocorrência de Brucella ovis e Brucella abortus nos rebanhos ovinos de municípios pertencentes à microrregião homogênea de Teresina, no estado do Piauí, Brasil.

\section{Material e Métodos}

Foram analisadas amostras de 521 animais oriundos de 28 rebanhos de 14 municípios pertencentes à microrregião de Teresina, no estado do Piauí, Brasil. Para a determinação do tamanho (n) de amostras, admitiu-se uma prevalência esperada da doença de $50 \%$ (correspondente a enfermidades de desconhecida ocorrência em determinada população), um nível de confiança de $95 \%$ e um erro tolerável de 0,05 . Quanto ao número de propriedades examinadas não foi aplicado nenhum critério de probabilidade.

As propriedades contempladas foram escolhidas em função do consentimento prévio dos proprietários. Em cada propriedade, participaram da amostra, de forma aleatória, um máximo de 20 animais por fazenda, constituído por $60 \%$ de matrizes, $30 \%$ de jovens (entre 6 a 12 meses) e $10 \%$ de reprodutores adultos.

A coleta de sangue foi realizada por venopunção e os tubos contendo as amostras foram encaminhados ao Laboratório de Fisiopatologia da Reprodução dos Animais Domésticos da Universidade Federal do Piauí para posterior análise. Para obtenção do soro o sangue foi submetido à centrifugação (3000rpm) durante 10 minutos. A pesquisa de anticorpos antiBrucella ovis e anti-Brucella abortus foi realizada por meio das técnicas de IDGA, e Antígeno Acidificado Tamponado (AAT).

Aos proprietários dos rebanhos foi aplicado um questionário contendo questões sobre os aspectos gerais da propriedade, do rebanho, além de informações sobre o manejo reprodutivo e sanitário dos animais. 


\section{Resultados e Discussão}

Não foram encontrados animais soropositivos para Brucella abortus em nenhuma das propriedades investigadas. Este resultado corrobora com os observados por Salaberry et al. (2011) que ao realizarem um estudo na cidade de Uberlândia, Minas Gerais, Brasil utilizando 334 amostras sanguíneas não evidenciou nenhum ovino soro-reagente para o mesmo patógeno.

De acordo com os dados obtidos no presente trabalho, $53,6 \%$ das propriedades investigadas apresentaram pelo menos um caso de ovino soropositivo para Brucella ovis pelo teste de IDGA. 4,6\% das 521 amostras analisadas pelo teste de IDGA para pesquisa de anticorpos antiBrucela ovis foram positivas (Tabela 1). Estes resultados diferem de Souza et al. (2012) que ao realizarem um inquérito soro-epidemiológico da presença de Brucella ovis em rebanhos ovinos do semi-árido baiano evidenciaram que $8,62 \%$ das propriedades avaliadas continham algum animal infectado e $0,72 \%$ das amostras estudadas foram positivas, demonstrando um alto índice de proliferação da doença em propriedades localizadas na região metropolitana de Teresina, Piauí, Brasil.

Tabela 1. Frequência de ovinos sorpositivos para Brucella ovis por município pertencente à microrregião de Teresina, Piauí

\begin{tabular}{lccc}
\hline Municípios & & \multicolumn{2}{c}{ Imunodifusão em gel de agar } \\
\cline { 2 - 4 } & $\mathrm{N}$ & Positivos & Negativos \\
\hline Lagoa Alegre & 23 & 4,34 & $(\%)$ \\
Teresina & 17 & 0,00 & 95,66 \\
Demerval Lobão & 20 & 0,00 & 100,00 \\
Lagoa do Piauí & 15 & 6,66 & 100,00 \\
José de Freitas & 122 & 0,00 & 93,34 \\
Monsenhor Gil & 80 & 2,50 & 100,00 \\
União & 55 & 1,80 & 97,50 \\
Nasária & 4 & 0,00 & 98,18 \\
Beneditinos & 56 & 8,92 & 100,00 \\
Miguel Leão & 16 & 12,50 & 91,07 \\
Curralinhos & 20 & 5,00 & 87,50 \\
Altos & 33 & 12,12 & 95,00 \\
Coivaras & 40 & 15,00 & 87,87 \\
Pau D’arco & 20 & 0,00 & 85,00 \\
Total & 521 & 4,60 & 100,00 \\
\hline
\end{tabular}

Em relação ao sexo, houve uma prevalência de $8,7 \%$ de fêmeas infectadas e $1,02 \%$ de machos. Analisando-se uma possível associação entre a frequência de animais reagentes para Brucella ovis e o sexo não houve significância estatística $(\mathrm{P}=$ $0,10)$ (Tabela 2). Com relação à idade dos animais soropositivos constatou-se $1,4 \%$ pertenciam ao grupo 1 (animais com idades entre 6 e 18 meses), $3,1 \%$ ao grupo 2 (animais com idades de 19 a 36 meses) e 13,6\% ao grupo 3 (animais maiores que 36 meses). Foi verificada associação estatística entre a frequência de animais positivos para Brucella ovis e a faixa etária $(\mathrm{P}<0,05)($ Tabela 3$)$. Os resultados obtidos no presente estudo, em relação ao sexo e idade dos animais avaliados são semelhantes aos descritos por Silva et al. (2009) que realizaram um estudo para detectar a ocorrência de brucelose ovina na região do recôncavo baiano, Bahia, Brasil e obtiveram diferenças estatísticas não significativas na amostra do estudo; porém, Pinheiro Junior et al. (2009) encontraram diferença estatística em relação ao sexo dos animais, onde $94,4 \%$ dos animais reagentes eram fêmeas e em relação à idade, apesar de ter sido constatada uma maior frequência em animais acima de 24 meses de vida, não houve diferenças estatísticas.

Tabela 2. Frequência de ovinos soropositivos para Brucella ovis de acordo com o sexo na microrregião de Teresina, Piauí.

\begin{tabular}{lccccc}
\hline \multirow{2}{*}{ Sexo } & \multicolumn{3}{c}{ Imunodifusão em gel de agar } \\
\cline { 3 - 6 } & & \multicolumn{2}{c}{ Positivo } & \multicolumn{2}{c}{ Negativo, } \\
\hline Machos & 98 & $\mathrm{n}$ & $\%$ & $\mathrm{n}$, & $\%$ \\
Fêmeas & 423 & 23 & 8,67 & 400 & 94,5 \\
\hline Total & 521 & 24 & 4,6 & 497 & 95,4 \\
\hline $\mathrm{P}=0,1069 ; \mathrm{n}=$ número total de animais & & &
\end{tabular}

Tabela 3. Frequência de ovinos soropositivos para Brucella ovis de acordo com a idade na Microrregião de Teresina, Piauí

\begin{tabular}{lccccc}
\hline \multirow{2}{*}{ Idade } & & \multicolumn{3}{c}{ Imunodifusão em gel de agar } \\
\cline { 2 - 6 } & & \multicolumn{2}{c}{ Positivo } & \multicolumn{2}{c}{ Negativo, } \\
\hline & $\mathrm{N}$ & $\mathrm{n}$ & $\%$ & $\mathrm{n}$, & $\%$ \\
\hline G1: 6-18 meses & 217 & 3 & 1,4 & 214 & 98,6 \\
G2:19-36 meses & 194 & 6 & 3,1 & 188 & 96,9 \\
G3: $>36$ meses & 110 & 15 & 13,6 & 95 & 86,3 \\
Total & 521 & 24 & 4,6 & 497 & 95,4 \\
\hline
\end{tabular}

$\mathrm{P}=0,0000 ; \mathrm{N}=$ número total de animais idade; $\mathrm{n}=$ número de animais de acordo com o resultado na IDGA

Quanto ao sistema de manejo, foi possível observar animais soropositivos em $63,3 \%$ das propriedades em que o sistema de criação era realizado de forma extensiva, em $33,3 \%$ dos animais mantidos sob sistema de criação semiintensivo, assim como em 33,3\% das propriedades que adotaram sistema de criação intensivo. Foi observada associação estatística entre a variável sistema de criação e a frequência de animais positivos $(\mathrm{P}=0,3355)$ (Tabela 4). Estes achados diferem de Clementino et al. (2007) que não 
relacionaram a ocorrência de brucelose ovina ao tipo de sistema de criação em um estudo realizado com 498 ovinos na região semi-árida do estado da Paraíba, Brasil. Martinez et al. (2010) avaliaram o tipo de sistema de criação em 58 propriedades pertencentes a microrregião de Juazeiro do Norte, Bahia, Brasil, evidenciando um elevado índice de criação em sistema extensivo, onde $89,6 \%$ dos rebanhos eram mantidos sob esse sistema, corroborando com os resultados obtidos no presente estudo.

A monta a campo foi identificada em 78,6\% dos rebanhos e a ocorrência de repetição do cio foi descrita em 39,2\% das propriedades. Em 28,6\% das propriedades foi relatada a ocorrência de abortos. Distúrbios reprodutivos relacionados à infecção por Brucella ovis também foram registrados por Pinheiro Junior et al. (2009), sendo de grande relevância o conhecimento da incidência de perdas relacionadas a reprodução devido as grandes perdas de produção que podem ser ocasionadas nos rebanhos ovinos do Piauí, assim como abortamentos que permanecem sem diagnóstico.

Tabela 4. Frequência de ovinos soropositivos para Brucella ovis de acordo com o sistema de criação na Microrregião de Teresina, Piauí.

\begin{tabular}{lccccc}
\hline \multirow{2}{*}{ Sistema de criação } & & \multicolumn{3}{c}{ Imunodifusão em Gel de Agar } \\
\cline { 2 - 6 } & & \multicolumn{2}{c}{ Positivo } & \multicolumn{2}{c}{ Negativo } \\
\hline Extensivo & 19 & 12 & 63,1 & 07 & 36,8 \\
Semi-intensivo & 06 & 02 & 33,3 & 04 & 66,6 \\
Intensivo & 03 & 01 & 33,3 & 02 & 66,6 \\
Total & 28 & 15 & 53,6 & 13 & 46,4 \\
\hline $\mathrm{P}=0,3355 ; \mathrm{N}=$ número total de rebanhos; $\mathrm{n}=$ número de \\
animais de acordo com o resultado na IDGA.
\end{tabular}

Em 96,4\% dos rebanhos, os ovinos eram criados em consórcio com outras espécies. Sobre o manejo sanitário, $89,3 \%$ das propriedades realizavam apenas a vermifugação e $7,1 \%$ não realizava nenhum manejo sanitário. $35,7 \%$ dos produtores vacinavam os animais contra clostridioses e $32,1 \%$ contra raiva. Marinho et al. (2012) também atentaram ao fato de que a maioria do rebanho ovino é mantida em consórcio com outras espécies, principalmente bovinos e equinos, em uma pesquisa realizada com ovinos procedentes de 49 propriedades da região noroeste do estado de São Paulo. Este mesmo estudo alerta para o déficit de um esquema imunoprofilático ovino específico, o que poderia aumentar os índices de vacinação nos rebanhos, inclusive os piauienses, assim como prevenir o uso indiscriminado de vermífugos e outras drogas.

Das criações de ovinos analisadas, as que recebiam algum tipo de assistência veterinária somaram 39,2\%. Alencar et al. (2010) ao realizarem uma pesquisa em 150 propriedades no sertão de Pernambuco, Brasil, identificaram um índice de $6,2 \%$ de assistência técnica contínua nas fazendas. Martinez et al. (2010) encontraram $58,6 \%$ de propriedades sem nenhum acompanhamento veterinário, o que demonstra a falta de investimento em assistência técnica especializada por parte dos criadores de ovinos no nordeste brasileiro, sendo este um fator que poderia contribuir na redução de perdas econômicas aos produtores.

\section{Conclusão}

Com base nos achados deste estudo pode se concluir que a microrregião de Teresina está exposta a contaminação por Brucella ovis e a implementação de melhores condições de manejo sanitário e reprodutivo são essenciais para o controle e prevenção da doença no estado do Piauí que atravessa uma fase de plena expansão da ovinocultura.

$\mathrm{O}$ investimento em assistência técnica especializada por parte dos criadores irá contribuir para uma maior profissionalização do segmento e diminuição da incidência de brucelose e outras doenças que causam grandes perdas econômicas

\section{Referências Bibliográficas}

Alencar, S. P., Mota, R. A., Coelho, M. C. O. C., Nascimento, S. A., Oliveira Abreu, S. R. \& Castro, R. S. 2010. Perfil sanitário dos rebanhos caprinos e ovinos no sertão de pernambucano. Ciência Animal Brasileira, 11, 131-140.

Clementino, I. J., Alves, C. J., Azevedo, S. S., Paulin, L. M. \& Medeiros, K. A. 2007. Inquérito soro Inquérito soro-epidemiológico e fatores de risco associados à-epidemiológico e fatores de risco associados à infecção por Brucella ovis em carneiros deslanados do semiárido da $\mathrm{P}$ semi-árido da Paraíba1. Pesquisa Veterinaria Brasileira, 27, 137-143.

Costa, E. A., Sant'Ana, F. M., Carvalho, C. J. S., Moustacas, V. S., Silva, S. M. M. S., Paixão, T. A. \& Santos, R. L. 2012. Diagnosis of Brucella ovis infection by serology and PCR in urine samples from naturally infected rams in the State of Piauí. Arquivo Brasileiro de 
Medicina Veterinária e Zootecnia, 64, 751754.

Lawinsky, M. L. J., Ohara, P. M., Elkhoury, M. R., Faria, N. C. \& Cavalcante, K. R. L. J. 2010. Estado da arte da brucelose em humanos. Revista Pan-Amazônica de Saúde, 1, 75-84.

Marinho, M., Mendes, L. C. N., Kaneto, C. N., Taparo, C. V., Bernardes, J. O. R., Lombardi, A. L., Perri, S. H. V., Baldasso, A. B. \& Ribeiro, M. M. 2012. Perfil de aglutininas antiLeptospira e anti-Brucella e condições sanitárias de ovinos da região noroeste do estado de São Paulo, Brasil. Veterinária e Zootecnia, 19, 593-600.

Martinez, P. M., Costa, J. N., Souza, T. S., Costa Neto, A. O. \& Pinheiro, R. R. 2010. Sistemas de criação de ovinos e ocorrência de anticorpos contra o vírus da Maedi-Visna na microrregião de Juazeiro, BA. 11, 2.

Pinheiro Junior, J. W., Oliveira, A. A. F., Mota, R. A., Agottani, J. V., Jesus, E. M., Assis, S. T. \& Oliveira, C. Z. 2009. Ocorrência de ovinos sororeatores para Brucella ovis no Estado de Alagoas, Brasil. Veterinária e Zootecnia, 16, 500-508.

Salaberry, S. R. S., Paulin, L. M., Santana, R. L., Castro, J. R. \& Lima-Ribeiro, A. M. C. 2011. Pesquisa de anticorpos anti-Brucella abortus e anti-Brucella ovis em ovinos no município de Uberlândia, MG. Arquivo Brasileiro de Medicina Veterinaria e Zootecnia, 63, 10221024.

Santos, C. S. A. B., Azevedo, S. S., Soares, H. S., Higino, S. S. S., Santos, F. A., Silva, M. L. C. R., Pena, H. F. J., Alves, C. J. \& Gennari, S. M. 2013. Flock-level risk factors associated with Neospora caninum seroprevalence in dairy goats in a semiarid region of Northeastern Brazil. Small Ruminant Research, 112, 239242.

Seleem, M. N., Boyle, S. M. \& Sriranganathan, N. 2010. Brucellosis: a re-emerging zoonosis. Veterinary Microbiology, 140, 392-398.
Silva, N. d. S., Barros, I. N., Dasso, M. G., Almeida, M. d. G. Á. R., Laborda, S. S., Anunciação, A. V. M., Moreira, E. L. T., Lima, A. E. S. \& Oliveira, E. M. D. 2009. Detecção de anticorpos anti-Brucella ovis em ovinos do estado da Bahia. Revista Brasileira de Saúde e Produção Animal, 10, 852-859.

Souza, F. G., Osório, A. L. A. R., Csordas, B. G., Prado, R. Q., Elisei, C., Soares, C. O., Araújo, F. R., Fragoso, S. P. \& Rosinha, G. M. S. 2009. Desenvolvimento e avaliação de uma cepa knockout de Brucella abortus obtida pela deleção do gene virB101. Pesquisa Veterinaria Brasileira, 29, 943-950.

Souza, T. S., Costa, J. N., Martinez, P. M., Lima, C. C. V., Araújo, B. R., Neto, A. C., Anunciação, A. V. M., Almeida, M. G. A. R. \& Pinheiro, R. R. 2012. Inquérito soroepidemiológico de Brucella ovis em rebanhos ovinos no semiárido baiano. Arquivos do Instituto Biológico, 79, 277-281.

Xavier, M. N., Sant'Anna, F. M., Silva, T. M. A., Costa, E. A., Moustacas, V. S., Merlo, F. A., Carvalho Júnior, C. A., Dasso, M. G., Mathias, L. A. \& Gouveia, A. M. G. 2011. A comparison of two agar gel immunodiffusion methods and a complement fixation test for serologic diagnosis of Brucella ovis infection in experimentally infected rams. Arquivo Brasileiro de Medicina Veterinária e Zootecnia, 63, 1016-1021.

\section{Article History:}

Received 30 January 2017

Accepted 22 February 2017

Available on line 30 April 2017

License information: This is an open-access article distributed under the terms of the Creative Commons Attribution License 4.0, which permits unrestricted use, distribution, and reproduction in any medium, provided the original work is properly cited. 